\title{
Where Does Pattee's “How Does a Molecule Become a Message?" Belong in the History of Biosemiotics?
}

\author{
Jon Umerez
}

Received: 7 April 2009 /Accepted: 30 June 2009 /

Published online: 17 October 2009

(C) Springer Science + Business Media B.V. 2009

\begin{abstract}
Recalling the title of Yoxen's classical paper on the influence of Schrödinger's book, I analyze the role that the work of H. Pattee might have played, if any, in the development of Biosemiotics. I take his 1969 paper "How does a molecule become a message?" (Developmental Biology Supplement) as a first target due to several circumstances that make it especially salient. On the one hand, even if Pattee has obviously developed further his ideas on later papers, the significance of this one springs out right from the title, the journal and date of publication and, of course, its content. On the other, this paper in particular has been somehow rediscovered recently and not only within the frame of biosemiotics (eg, in history and philosophy of biology by E.F. Keller). Following the parallelism with Yoxen's perspective, I contend that Pattee's work was relatively influential with respect to a good amount of attempts to rethink living systems within theoretical biology around the 70s. This influence diminished together with the decay or even collapse of those attempts under the impact of molecular biology as it was being developed those years. Eventually, Pattee's work has been taken up again. Notwithstanding, it is quite clear that Pattee himself was not intending to contribute specifically to Biosemiotics and that he was probably unaware of any such discipline, at least until recently. Then, we should as well ask (as Yoxen wonders with respect to Schrödinger) to which extent Pattee's influence has been a direct one or rather an indication of the relevance of his ideas and the resonance of his hypotheses with those of biosemiotics. For this task I will sketch a few points of
\end{abstract}

Revised and expanded version of a talk delivered at the 2003 Meetings of the International Society for the History, and Social Studies of Biology (ISHPSSB '03), session on "Biology and Meaning", Vienna, 16-20 July 2003.

J. Umerez $(\bowtie)$

Department of Logic \& Philosophy of Science, IAS-Research-Philosophy of Biology research group, University of the Basque Country (UPV/EHU), Tolosa hiribidea 70,

Donostia (Gip.) E-20494 Basque Country, Spain

e-mail: jon.umerez@ehu.es 
convergence and divergence and examine the work of some authors who either address directly this issue or have contributed significantly to build up the history of Biosemiotics.

Keywords Semantic closure - Epistemic cut - Semiotic $\cdot$ Complementarity Code Control · Dynamics

\section{Introduction}

This is not as much a paper on conceptual issues. I have addressed some of those in other places (Umerez, 1995, 1998, 2001a; Ruiz-Mirazo et al. 2008). It is more an attempt to locate Pattee and his proposals in a more encompassing historical framework that takes into account more recent developments. This would be, then, the first part of a project to situate Pattee with respect to certain issues and areas of research to which his ideas are related. In this sense, I intend here to place him in relation to Biosemiotics and examine his potential contribution to the field. I have taken into account that his approach to the understanding of life is built around a set of concepts, such as 'semantic closure', 'epistemic cut', symbol/matter relation, code, language, etc., that seem to be quite congenial to those of Biosemiotics.

In order help me in conveying the point, I have found it convenient to use some scaffolding. To this end, I have resorted to a paper by Yoxen assessing Schrödinger's contribution to molecular biology (Yoxen 1979), which offered me a clue regarding how to approach this study. It gave me the idea to follow his methodology by asking about the reception of Pattee's early and fundamental work: how, when and by whom had it been read? In that article, Yoxen examined Schrödinger's 1944 book, What is life?, and its influence in the inception of contemporary molecular biology through the use of informational and code related terms and concepts. In particular, the issue is that classically it has been considered that the influence of that book, centered on the mention of the notion of code-script and the comparison with an a-periodic crystal, was determinant in the direction taken and the conceptual development of molecular biology. But Yoxen failed to agree and argued his case.

Let me make sure, from the beginning that I am not intending to draw or even suggest any unjustified equation: not Pattee with Schrödinger or the book of the latter with the papers of the former, neither Biosemiotics with Molecular Biology or their respective influence in those disciplines (and much less a qualified historian as Yoxen with myself). Nevertheless, besides the heuristic utility of the analogy with Yoxen's work, there are also other similarities between the two authors, for instance, those regarding general motivation and approach. On the one hand, Schrödinger was a physicist who become interested and worried about understanding life (see e.g., Moore 1989, p. 394-404) and this has been precisely Pattee's main motivation, being himself a physicist as well. On the other hand, their approach to this issue is equally molded by the tools of their discipline of origin: physical laws, order, specificity, entropy, ... and even, though they diverge here, complementarity of a Bohr-ian ancestry in Pattee's case. 


\section{Yoxen and his Demithologizing}

Edwad J. Yoxen published in 1979 in the journal History of Science a paper entitled "Where does Schrödinger's 'What is Life?' belong in the History of Molecular Biology" where he discussed the received view regarding the influence of that book on molecular biology, specially according to the accounts and recollections of the scientists themselves. In his own words, his purpose is the following:

"My argument (...) falls into three sections. In the first I want to review the reactions to the book from the time of its publication to recent comments by molecular biologists about it. The second section is concerned with the details of Schrödinger's biography, involving a close examination of his motivation and inspiration in writing the book, (...) The intention is to reveal the contrast between Schrödinger's perception of the book and molecular biologists' accounts of it in recent years. It is argued that Schrödinger's real purpose has been obscured by concentration upon that part of "What is Life?" concerned with the genetic code. In the third section I consider how the book might be recontextualized ..." (Yoxen 1979, 19)

In particular, Yoxen will try to counter the standard view as exemplified, for instance, in Olby's history of the beginning of molecular biology, The Path to the Double Helix (1974[1994]), where he asserts that

"We come now to what we can see in retrospect as the most positive and influential aspect of this little book: the concept of an hereditary codescript" (Olby 1974[1994], 246)

It is this particular point that is questioned, the role of Schrödinger's book as a precursor of ensuing informational approaches, not the general influence of the book which seems to have been quite widely read. The other contemporary massive history of the new field, Judson's more journalistic The Eight Day of Creation (1979[1996]), is less categorical in endorsing this evaluation of the book (see, for instance, pp. 244-245), beyond showing clearly the fact that many researchers read it and that it was very influential in moving them (specially physicists) into biology ${ }^{1}$.

In his paper, Yoxen defends that Schrödinger's main motivations where other (those related to order, entropy, specificity),

"The evidence suggests that he was more concerned with the problem of lawfulness in biological systems than with the structure of the gene. There is no reason to suppose that he regarded his "remarks" on a "hereditary codescript" as anything other than a subsidiary part of the argument, surprising

\footnotetext{
${ }^{1}$ More recent book-length contributions as, for instance, Kay (1993), Morange (1994[2003]), Sarkar (1996), de Chadarevian (2002) are, in general, not conclusive, still conveying the standard view but quite tempered.
} 
as this may now seem given the prominence that the gene is accorded in biological theory" (p. 36)

Yoxen defends therefore that the immediate influence of the book was somehow different and that only in the 1960s Schrödinger began to be cited, somehow wrongfully, as a father of the emerging code/information paradigm. Lily Kay (2000), who is sympathetic to Yoxen's indictment, in referring to previous ideas of code or similar kind of representations, summarizes as follows:

"Nevertheless, in retrospect, the representations have been commonly attributed to the singular impact of Erwin Schrödinger's little book What is Life? (1944), through which his historical role was reinvented. (...) Of all the insights and foresights attributed to Schrödinger, the crowning achievement bestowed upon him is that of progenitor of the genetic code and information prophet of molecular biology" (Kay 2000, 59)

In summary, letting aside the specific historical point regarding What is life?, what I would like to retain from this case is that, according to Yoxen and Kay, Schrödinger was only re-read, a posteriori, as precursor of the informational perspective in Molecular Biology in particular, while his contribution could well have been just a more general and imprecise one. It is my purpose, then, to ask whether some sort of re-reading may have been going on regarding Pattee within or around a broadly understood field of biosemiotics. A re-reading that may well acknowledge him as a precursor but take only partially his message or reinterpret it through a contemporary biosemiotic perspective. To this end I will briefly sketch a few points of convergence and divergence with biosemiotics regarding important issues that characterize currently the field or are still debated. However, I cannot pursue those issues in detail here and I will just inquire (as Yoxen wonders with respect to Schrödinger) to which extent Pattee's influence has been a direct one or rather an indication of the relevance of his ideas and the resonance of his hypotheses with those of biosemiotics.

\section{What About Pattee?}

Pattee's work has clear connections with that discussion regarding the role of Schrödinger's book. On the one hand, to begin with, what makes me connect this is that Pattee himself was mainly motivated by his awe with the difficulty to properly understand fully life with physical laws, which any living system does anyway abide by.

"By 1970, there was no longer much interest in possible paradoxes or revisions of physical theories to accommodate living systems." (Pattee 2001a, 6).

Even if Schrödinger's contribution could be considered more physicalist or reductionist (as, for instance, Gould 1995 does), let us note that this is precisely what Schrödinger was looking for: a more encompassing understanding of physics in order to take in life itself. Pattee, on the other hand, without being a physicalist, does not want to relinquish going as far as physics can lead us. 
In his paper within the special issue of the journal Biosystems dedicated to his work $^{2}$, Pattee opens the paper with a quotation from Karl Pearson's Grammar of Science (1892) in which Pearson wonders how is it possible for us to distinguish the living from the lifeless. In this sense, we may just take notice of how Pattee himself has insisted on that

“...his underlying motivation has been the question: How can we explain why life is different from physical systems if life is just matter that must follow physical laws? As he rightly notices, this is a question that, in general, bothers physicists more than biologists or philosophers.” (Umerez 2001a, 161-2)

Nevertheless, there are further points of divergence beyond this coincidence of approach at a very general level. According to Olby, the interest or enthusiasm of some for Schrödinger's "a-periodic crystal”, contrasts with his negative feeling about Bohr's complementarity (Olby 1974[1994], p. 247; Moore 1989, p. 473). Curiously, Pattee found one of his most important influences precisely in Bohr's idea (see, among others, Pattee 1967, 1977, 1978, 1979, 1982), while he almost does not refer to Schrödinger's book at all, even if the idea of code is really an important and basic one for him. Well, he does cite this book sometimes but not as often as Bohr and, more important, in general to refer to Schrödinger's analysis of order and reliability, not the code -script. In this, according to Yoxen, he would have been reading the book properly.

\section{The Paper ("How Does a Molecule Become a Message?")}

The choice of this particular paper by Pattee as the focal point around which to organize this work attempting to assess Pattee's relation to Biosemiotics is due to several relevant and significant elements as its title, the place/journal of publication, the year, and the fact that it has recently been the object of an interesting case of recuperation within a more wide field of research.

The paper, entitled "How Does a Molecule Become a Message?", appeared in Developmental Biology Supplement volume 3, pages 1 to 16, as a result of the 28th Symposium of the Society of Developmental Biology, edited by Lang in $1969^{3}$. Besides the wording of the title which speaks by itself, the place of publication is also important since it amounts to a contribution to developmental biology in those times when this discipline was, if not marginal with respect to Molecular Biology, far away from the position of centrality that has finally gained in recent times. Similarly, the late sixties were a difficult time for non standard molecular biological approaches. Notwithstanding, at the same time, it was probably the only moment in several decades earlier and later where a little window of possibilities were open for un-orthodox positions in theoretical biology to have an audition through at least

\footnotetext{
${ }^{2}$ Meaningfully entitled "The Physics and Evolution of Symbols and Codes — Reflections on the Work of Howard Pattee" (Rocha 2001a)

${ }^{3}$ Actually the paper appeared in the 3rd volume of conference related supplements to the journal Developmental Biology which was a quite recent one as Keller notes (1995 p. 110) but not as much as she says, since it was already a decade old, having published their first issue in April 1959 (they are just celebrating their 50th anniversary this year, see Developmental Biology 325 (2009) 1-3)
} 
some gatherings and publications. We may surely identify as their pinnacle the series of conferences organized by Waddington at the end of the 1960s Towards a Theoretical Biology and published subsequently $(1968,1972)^{4}$.

Moreover, as the author remarks, the theme of the symposium at which he contributed this paper was, quite tellingly, "Communication in Development". This obviously adds a further point of connection with the general question I am addressing in this work, the relation of Pattee to biosemiotics, and reinforces the choice of this particular paper as its specific subject matter.

The paper begins by establishing a connection between the understanding of communication in developmental biology, which may well go without a precise definition as far as experimental questions are involved, with Pattee's own interest, as an outsider interested in the origin of life, who is "convinced that the problem of the origin of life cannot even be formulated without a better understanding of how molecules can function symbolically, that is, as records, codes, and signals" (p. 1). Hence the title of the paper. More specifically he will try to distinguish, always at the simplest level, communication between molecules from mere physical interactions between molecules. He insists that it is not the same to know how something works and to understand how it originated (life itself to begin with, every evolutionary innovation, a new level of control, ...) and therefore claims the necessity of constructing theory together and beyond just collecting more data. In this sense he thinks it is necessary to develop a "theory of the origin of hierarchical organization" (p. 2) together with experiments showing how linguistic constraints may arise from physical constraints. He ends setting up the problem with the exposition of his working hypothesis:

"Therefore it is reasonable to consider the hypothesis that the first "messages" were expressed not in the highly integrated and precise genetic code that we find today, but in a more global set of geophysical and geochemical constraints, which we could call the primeval "ecosystem language", from which the genetic code condensed in much the same way that our formal rules of syntax and dictionaries condensed from the functional usage of primitive symbol in a complex environment. If this were indeed the case, then it would be more likely that "developmental replication" in the form of external cycles not only preceded autonomous "self-replication", but may have accounted for the form of the genetic code itself." (p. 3)

In the next section he discusses "some properties of languages and symbols", centered on the arbitrariness of rules common to languages and messages, even if he recognizes that "[t]he arbitrariness in primitive biological languages is less clear" (p. 4). Nevertheless, from the prevalence of the frozen accident theory of the code, he connects this issue of the origin of arbitrary rules with a result of his work in hierarchy theory stated as a principle of impotence: "Hierarchical organizations obscure their own origins as they evolve" (p. 4). This principle is due to a simplification or loss of detail that he attributes to any hierarchical control. From this he extracts a preliminary answer to the question of how to distinguish communication form normal interaction: “... one necessary condition for the appearance of a

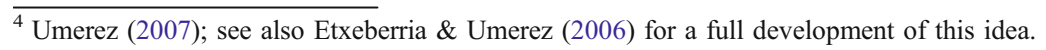


message is that very complex interactions lead to a very simple result" (p. 5). Then he turns to ask "What is the simplest message?" and, since it seems that most related terms in biology might be simplified to meaning "turn on" or "turn off", he notes that the simplest device able to perform such operation takes then the form of a switch and highlights the remarkable speed and reliability of such natural switches as enzymes (p. 6). Next, we arrive to the central section on the paper on "What is the simplest natural language?" where he notes that "an isolated switch in nature (...) would have no function (p. 7) so the question of how large need a system to be for functions to arise is introduced:

“... if we consider life as distinguished from nonliving matter by its evolutionary behavior in the course of time, then it is clear that the isolated cell is too small a system, since it is only through the communication of cells with the outside environment that natural selection can take place. The same may be said of developmental systems in which collection of cells create messages that control the replication and expression of individual cells". (pp. 7-8)

This question is naturally present as well at the problem of the origin of life, where opposite views dispute the precedence of nucleic acids over proteins (enzymes) or vice versa and Pattee suggests a complementary version he has defended in his previous work on the origin of life in terms of a "primeval ecosystem"5.

As the "conclusion" in the middle of the paper makes quite clear, we reach now the main thesis of the paper; the answer, at least in the negative, to the question in the title in unambiguous semiotic terms: the relational nature of any message, the condition of being relative to a context and not something absolute:

"But these speculations are not my main point. What I want to say is that a molecule does not become a message because of any particular shape or structure or behavior of the molecule. A molecule becomes a message only in the context of a larger system of physical constraints which I have called a "language" in analogy to our normal usage of the concept of message." (p. 8)

Nevertheless, the distance from (bio)Semiotics is seen form the very beginning: "... in analogy to our normal usage of the concept of message" (Pattee 1969, p. 8). Pattee is aware of the difficulties of his proposal and, in certain sense, this already sets the framework in a non-semiotic (as discipline) arena as we will later discuss in Section "Some Divergences and Convergences":

"The trouble with this analogy is that our human languages are far too complex and depend too strongly on the structure and evolution of the brain and the whole human organism to clarify the problem. We are

\footnotetext{
5 "I find it more reasonable to begin, not with switching mechanisms or meaningless messages, but rather with a primitive communication network which could be called the "primeval ecosystem". Such a system might consist of primitive geochemical matter cycles in which matter is catalitically shunted through celllike structures which occur spontaneously without initial genetic instructions or metabolic control. In my picture, it is the constraints of the primeval ecosystem which, in effect, generate the language in which the first specific messages can make evolutionary sense.” (p. 8)
} 
explaining the most simple language in terms of the most complex. Anyway, since the origin of language is so mysterious that linguists have practically given up on the problem, we cannot expect any help even from this questionable analogy." (8-9, my italics)

The paper continues with two interesting sections on "the simplest artificial languages" and "on the simulation of origins" where he discusses well known cybernetic classical models together with more recent ones as, for instance, those of Wolpert, Conrad or Kauffman or some of his own. There is a final concluding section on "the role of theory in biology".

It is no surprise that this paper is situated among a group of related and very decisive works by Pattee during those years on the conditions for the origin of life and heredity, hierarchies and, of course, coding (see Umerez 2001a for a review and Umerez $2001 \mathrm{~b}$ for a bibliography). As a unique example, taken from his influential contribution to the first Waddington's Symposia, let's quote a passage where Pattee complements his view by making explicit the connection to von Neumann's (1966) logic of description and construction:

"The process of cellular replication and in particular the development of the organism may be interpreted as an entire system construction process which requires a coding mechanism which interprets as well as replicates a description. Largely from studying the logic of abstract automata we may begin to appreciate how, through the discovery of simple codes, it is possible to generate elaborate ordered structure from relatively concise descriptions. Such a description-codeconstruction process cannot be adequately characterized as either preformation or epigenesis, since on the one hand the construction may be totally unlike its description, whereas on the other hand the description and code structure together provide a complete, autonomous generation of the phenotypic construction within the crucial limits of reliability. At the evolutionary level this concept of a symbolic genetic description and its code structures must be broadened to a larger system which includes not only the description of the system itself but also a description or a 'theory' of the environment. In the evolutionary context the phenotype itself now plays the role of a composite measuring device which tests the descriptive theory through its interactions with the real environment." (1968, 89-90)

Later on he has frequently re-stated and developed the ideas of his 1969 paper and he has explicitly mentioned it as a key reference for his understanding of symbols: "I define a symbol in terms of its structure and function (...) Symbols do not exist in isolation but are part of a semiotic or linguistic system (Pattee 1969)" (Pattee 2001a, p.10 n. 6). In those occasions in which he has recently re-examined his work of the 60 s and this paper in particular, he is able, on the one hand, to maintain the accuracy of his approach while being, on the other, quite critical and not pretending to have solved the symbol-matter relation issue (e.g., 2001a, pp. 9-11; 2001b, pp. 347-348; 2005, p. 283; 2007 , p. 2273 ; 2008b, pp. 148,152 , 158). Precisely, in his contribution to the special issue of the journal Semiotica honoring Jakob von Uexküll he says the following:

"The title of one of my first articles, 'How does a molecule become a message?' (...) asked the important question, but the article gave no good answer" (Pattee 2001b, 347). 
Almost 40 years later we should perhaps assess the virtues of that paper (and related work) more encouragingly since, while it might be true it did not provide a good answer to the problem of origins (how it actually originated), it certainly put forward an excellent and fertile framing for the issue, characterizing (more rightly than any then and more rightly than many now) the sense of 'message' (symbol, language, control, etc) referred to DNA.

Finally, this paper also is the main protagonist of a certain recovery of Pattee's work within the field of the history and philosophy of biology (mainly molecular biology, something quite recent in contrast with the more common philosophy of evolutionary biology), specially through the work by Evelyn F. Keller (1995, 2000, 2002) who cites and quotes among others this paper in particular. Other authors also recover Pattee's ideas in this context, whereas nor recalling this specific paper (it is common to quote his contribution to the fourth TTB, Pattee 1972) neither being as sympathetic.

\section{References: From Waddington (1972) to Keller (2000)}

Continuing with the title paper we may also ponder how it fared contemporarily and study its singular fate since its publication 40 years ago.

First of all, I would like to highlight that this article's question and its pointing to an answer in terms of language (in a very general sense), was used by Waddington himself, who takes ground explicitly on Pattee's proposals in order to build up the general and closing conclusions to the four symposia in the epilogue to the series:

"Now the living world, as Pattee points out, is founded on a dualism of a kind which can be regarded in this way. At a relatively simple level, we have the genotype, of relatively unreactive DNA, in which no one could workup much interest were it not that it can act as a symbol coding for the much more reactive phenotype, the proteins which perform operations on their surroundings. It is on the phenotypes that our immediate interest is directed as natural predatory members of the biosphere. So is that of natural selection; (...). Returning to Pattee's essay; he argues that a symbol can only function as such when it is part of a system of symbols. A word must be a word in a language. To his own question 'How does a molecule become a message' he answers that it is inadequate to say 'when it codes for some other molecule in which we are more interested', as a nucleic acid may code for a protein; such a reply tacitly assumes the existence of ribosomes, polymerases, activated aminoacids and so on-a whole linguistic apparatus, a grammar. The 'structures mediating global simplicity' which we have to search for in the theory of general biology are, then, perhaps profitably to be compared with languages; based on the primary biological disjunction between genotype and phenotype as the analogue of symbol-symbolized, but going as much beyond it as a structured grammar is beyond a single word. And once we have a language, we can have a metalanguage; we can define one word in terms of a set of other words." (Waddington 1972, pp. 285-286)

Since then, several authors have mentioned Pattee's proposals but quite seldom referring to the 1969 paper. Instead, it is much more frequent to find references to his 
contribution to the fourth Towards a Theoretical Biology symposium (Pattee 1972), which he introduced as a further development of the issues considered in that paper.

We may recall that Pattee was well known in the 1960s and the 1970s in several fields (Umerez 2001a). First of all, within what remained of a Theoretical Biology that attempted to transcend mere formalism and mathematical modeling in order to provide wider ways to understand and explain life's complexity (as we have seen, Waddington's Towards a Theoretical Biology series of symposia and their subsequent published proceedings meant, in a sense, the pinnacle of this endeavor). Besides, he was also recognized in several frontier areas as those of origin of life studies and, more generally, hierarchy theory. Despite the fact that his approach was already taking form around the issue of the relations between symbol and matter, it is not this central aspect which is mainly considered, with some exceptions, and therefore his 1969 paper is no frequently cited if ever. In the 1980s and in the 1990s, even if at a lesser extent, he continues to be cited but, again, with small exceptions, the same pattern remains, more attention to his suggestions for understanding the origin of life, his theory of hierarchies or general mentions to complementarity and constraints than to the overall epistemological (semantic/semiotic) frame and to his original view of genetic control as a semantic closure which takes into account dynamic as well as informational aspects within the context of the cell.

Those exceptions come, on the one hand, from sympathizers or fellow travelers in different fields, generally critical with standard, mainstream biological thought: followers of autopoiesis and autonomy based approaches (Moreno et al. 2008), proponents of structuralism and developmentalist views, remaining theoretical biologists, etc. As well, in newer fields as Artificial Life, situated or embodied Artificial Intelligence and Robotics, and diverse areas in the complex systems studies constellation, some authors begin to take also into consideration this semiotic aspect of Pattee's work though it is not yet the main one. Even something like a proto-school of Patteeans began to be discernible through several dissertations, gatherings and publications ${ }^{6}$.

On the other hand, we may also find some hesitant (not condemnatory but mostly skeptical) allusions in authors critical with the prevalence of genetic constituents in expressions like genetic program, code, information etc., in detriment of metabolic and developmental ones. A very representative example is Oyama's judgment that Pattee's work might have gone in the right direction but was hindered by relying on linguistic concepts in her influential The Ontogeny of Information (1985, p. 45). A similar more recent assessment is that of Moss (2003) who still has reservations regarding the prospects of "giving the language metaphor a dialogic, or at least contextual, turn” (p. 73) when assessing Doyle's (1997) proposal based on Pattee.

Also quite recently, and mainly in the context of Evelyn F. Keller's interest in the metaphors and models used by last century biology (in particular genetics and developmental biology, and their mutual interweaving), has this precise paper (and Pattee's approach) been rescued for a wider audience in the history and philosophy of science. In coincidence with the beginning of the recent discussions within the

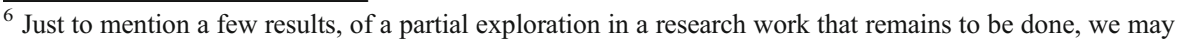
mention some dissertations as Kelly (1987), Minch (1988), Cariani (1989), Waters (1990), or groups of contributions in several special issues as those edited by Rocha (1995 in CC-AI and 2001a in BioSystems) or collective volumes as as those compiled by van de Vijver et al. (1998) and van de Vijver \& Chandler (2000).
} 
philosophy of biology regarding the status of information, Keller has more than once noted Pattee's work as of a different kind:

"However, some (distinctly nonmolecular) biologists saw a quite different and perhaps more profitable use to be made of the models the new machine had to offer. Instead of claiming the notion of information to support a highly reductionist and unidirectional causal structure, a small number of biologists interested in the complexities of embryogenesis sought in cybernetics and information theory support for a dynamic and interactive conception of organism. Although these efforts are now largely forgotten, and were not at the time followed up, they are nonetheless worth noting, if only for historical interest.” (Keller 1995, p. 99)

Among those she mentions explicitly Pattee and the question of the paper we are dealing with, which, according to her, even if it has not yet been answered, meant a new departure (Keller 1995, p.110). She also mentions the paper when, at the end of the second chapter of her review of the changing notion of the gene (Keller 2000), she remarks that another lesson of current genetics is that the understanding of gene function is also to be done in dynamical terms and closes the paragraph saying that "... the question that dominates the attention of molecular geneticists today" might be put “... as a paraphrase of...” Pattee's 1969 one (Keller 2000, p. 71-72). Finally, in her last book (2002), she again quotes Pattee, now in relation to Artificial Life and bringing out another paper (Pattee 1989), but again to notice his pointing to the "fundamental relation between symbol and matter" (Keller 2000, p. 287) as the main problem to be addressed by the new discipline.

Other authors in this area have recently continued to take some notice. For instance, Rheinberger $(2000)^{7}$ mentions the paper in order to highlight the importance of the (biological) context if we try to account for the meaning of the genetic level (p. 234-5).

We turn, finally, to our target and final station in this tour, Biosemiotics, a milieu where Pattee's 1969 paper and his epistemic approach is finding, naturally, a wide and deep response. But, in any way, quite a recent one too, beginning in the 1990s (probably with Emmeche \& Hoffmeyer 1991) and taking pace mostly at the turn of the century, when he is rescued as a forerunner of biosemiotics, even if of a particular kind.

\section{What About Semiotics?}

Almost contemporarily with Beadle \& Beadle connecting of life and language (1966) or even with Rotschild's alleged first use of the term (1962, see Kull 1999a) and, clearly, years before the other christenings of the field (Stepeanov 1971, Florkin 1974; see, for instance, Barbieri 2008d, Favareau 2008), Pattee was already advancing and developing, in an independent way, concepts and ideas that cannot but be considered as resonating with some of those which will later become the

\footnotetext{
${ }^{7}$ Precisely in his contribution to the collective volume on The Concept of the Gene in Development and Evolution edited by Beurton et al. (2000).
} 
core of Biosemiotics. Therefore, despite the fact that the idea behind biosemiotics might be traced back to the discovery of the genetic code in the first half of the 1960 s, pointing as an indicator to the book by Beadle \& Beadle (1966) as Barbieri (2008c) does, if we just look to dates it is obvious that very important papers by Pattee (including the one I am using as a reference point) pre-date the inception on anything like a new field of research. Notwithstanding, the originating connection for the field of Biosemiotics with the discovery of the genetic code that Barbieri makes is a kind of link avant la lettre with the work of Pattee that only later will be made apparent.

For years, while Biosemiotics was beginning to grow and develop, they were mutually unknown. Later on, when the new field is getting some momentum and begins to reconsider its resources (antecedents, forerunners and disparate fellow travelers) they start to notice Pattee and include him in reviews and historical reconstructions. Eventually, Pattee himself begins to endorse somehow the connection and initiates a dialogue.

In order to examine this process we may take a few relevant examples from different periods. For instance, on the conceptual side, the fundamental paper by Hoffmeyer \& Emmeche (1991) on code duality, which is one of the first references in a biosemiotician context to Pattee's work, does not mention the 1969 paper and Pattee himself is cited directly just once noticing his defense of the necessity of a description as a basis for self-refence (p. 126) citing two papers (one of them is the already mentioned contribution to the IV TTB of 1972) and they again refer to one of this papers (Pattee 1977) while introducing a sort of Polanyi's 'tacit knowledge' (p. 127). In a quite complementary paper to that one by the same authors ("From Language to Nature", Emmeche \& Hoffmeyer 1991), they introduce Pattee in relation to the origin of life problem asserting that "... it has been a central idea to Pattee in dealing with these problems during the past two decades, that the essence of the matter-symbol problem and the measurement or recording problem must appear at the origin of life" and they quote the 1969 paper (together with other two). Emmeche himself, in another important paper that year (Emmeche 1991), had made a reference to Pattee's "dynamical mode" as a reminder of the importance of materiality when symbolic structures are to be interpreted (p. 337).

Notwithstanding, in a revision of the code duality paper, 10 years later, author and leading biosemioticist Jesper Hoffmeyer (2002, p 106 ff.) counts already Pattee as a "major precursor". In addition, in the foreword to the reprinting of that paper, together with co-author and also leading biosemioticist Claus Emmeche, they note that " $(\mathrm{t})$ he idea of code duality itself owed a lot both to Gregory Bateson and to Howard Pattee" (Emmeche \& Hoffmeyer 2005, p. 35).

On the historical side, Kalevi Kull for instance, in his paper on "Biosemiotics in the twentieth century: a view from biology" (1999b), counts Pattee among "the proponents of biosemiotics" (p. 386) when he begins his review by mentioning the approaches of a few selected authors. Nevertheless, it is quite curious to notice that, later on in his review, when he describes the situation during the "1960s and after", he does not refer directly to him or to any of his papers (in a particularly productive period for Pattee), but he does mention Waddington or Rosen. It is precisely in the context of recalling the already mentioned series of symposia organized by Waddington (1968-1972), that he mentions Pattee again 
"as one of the participants" who develop the ideas reflected on Waddington's conclusion assessing that

"... the paradigm for the theory of general biology was sought. According to the conclusion made by the organizer of these conferences C.H. Waddington, this paradigm should come from general linguistics (Waddington 1972)." (Kull 1999b)

But here, apparently, the reviewer doesn't realize that precisely this aspect of Waddington's conclusion is directly and explicitly taken from Pattee's contributions, as we have seen earlier with the full quotation of a relevant passage from this conclusion (Waddington 1972). Kull was anyway quite right in saying that "[d]uring the 20 years since the Waddington's conclusion, there was not very much done in biosemiotics from the standpoint of the theory of general biology" (Kull 1993, p. 53)

Recently, a good deal of further historical research and comprehensive reviews of the field has been appearing (Kull 2005, Sebeok 2001, Barbieri 2008d, Favareau 2008 , etc.) which expand the consideration of Pattee as a forerunner and distinguish his from other approaches where mere affinities are identified. Besides, it seems that some kind of agreement is growing around the idea that the current field has a multiverse origin with several lines of research or schools but broadly coalescing into two main approaches that finally converge in the past few years, despite their differences, according to some authors ${ }^{8}$.

A straightforward expression of this is apparent in Barbieri's recent review of the field for the journal Naturwissenschaften, where he distinguishes mainly two views: "code-based biosemiotics" coming out of the discovery of the genetic code and "sign-based biosemiotics" stemming from the appreciation that the human being is not unique as semiotic animal (Barbieri 2008d, 594-596). According to Barbieri, the first view threads the connection of (biological) code and language by Beadle \& Beadle (1966), through the labeling of biosemiotics as the study of molecular language (Florkin 1974), with Barbieri himself and his proposal of a cellular code (1981). The second view would initiate with Sebeok's proposal of Zoosemiotics $(1963,1972)$ continuing with his work within the field of Semiotics and converging with Hoffmeyer in a line that would include Rotschild (1966) and Stepeanov (1971). Besides these two main schools, the review specifies three individual further ones: those of Bateson, Markos and Pattee (Barbieri 2008d, 596). In an almost parallel reconstruction in his introductory Editorial to the new journal Biosemiotics (Barbieri 2008c), he incorporates Markos within a broad group that consists of, using his labels, the initial Peirce-Sebeok model, the Copenhagen-Tartu school (Hoffmeyer, Emmeche, Kull, etc.) and the Prague school (Markos). This group would diverge from another one personified by Barbieri himself on the issue of interpretation, i.e., whether it is or not necessary to understand the triadic relation supporting the biological code(s) in terms of interpretation. This time, Barbieri introduces only Pattee's approach as a separate third line which addresses the physical conditions for

\footnotetext{
${ }^{8}$ Several mentions to a meeting among some leading biosemioticists in the context of the fourth Gathering in Biosemiotics in Prague, in July 2004, where a programmatic unification in terms and content was agreed upon (see, for instance, Barbieri 2008b, 2008d).
} 
codes and symbols and draws an epistemic threshold coincident with the origin of life (Barbieri 2008c, 2) ${ }^{9}$.

Just to mention a last recent example of historical reconstruction, we may choose the also quite official one by Favareau (2008), which is congruent with Barbieri's classification. Favareau inserts his narrative in a general scheme of the changing relations between signs and science going back to Aristotle. The contemporary final point of his history centers first on the fundamental role of Thomas Sebeok since the 1960s and then on the crucial meeting with Hoffemyer at the beginning of the 1990s that, according to him, marks properly when Biosemiotics takes off as a discipline. Together with this line Favareau also follows the development of critics to it and introduces Barbieri's approach as the main alternative view. In between, Favareau has considered a group of "other" authors among whom he examines Pattee and meaningfully highlights his “... precisely articulated questions” (Favareau 2008, 43).

In those historical accounts, Pattee begins to appear as another fundamental though independent line of research convergent with more central ones and his 1969 paper pops up ever more often in the lists of references. Nevertheless, I think Favareau (2008) is quite right in assessing the significance of most forerunners, when he says that the work, the people or even the meetings around Theoretical Biology did not build up anything as a coherent new area of research and, naturally, this may well go for Pattee too. Likewise, he notes that "no interdisciplinary movement resulted from [the] individual efforts" of Florkin (1974), Rotschild (1962) and Stepeanov (1971) who independently coined the term biosemiotics (p. 55). Instead, for Favareau, the encounter between Sebeok and Hoffmeyer in 1990 is going to fuel a movement that he describes as irradiating from Copenhagen and leading through several workshops to the International Gatherings starting in 2001 precisely in Copenhagen (and later in 2005 to the first journal and the society).

Nevertheless, it is no doubt that there is a strong connection via the sharing of many terms, concepts, issues and projects between Biosemiotics and Theoretical Biology (Waddington's way), within which we can safely and explicitly locate Pattee. But his connection to biosemiotics has become even more direct. In this sense, it is highly significant that as many as four of his few recent papers have appeared in explicitly biosemiotics publications and in direct dialog with the field ${ }^{10}$. Besides, he began to use the term semiotic (instead of or together with epistemic sometimes and semantic some others) since his 1995a paper and with a heavy use in his 1997 contribution, but seemingly incorporating an expression used by Luis Rocha (2001b), rather than through a direct influence of the literature on biosemiotics (see, Pattee 2005, 296 or 2008a, 127)

This circumstance may mark a last difference with respect to Schrödinger's relation to Molecular Biology inasmuch as Pattee is having the opportunity to

\footnotetext{
${ }^{9}$ The value of Pattee's work is highlighted even more in a manuscript by Barbieri, "A Short History of Biosemiotics" (2009), where he actually begins with Pattee's contribution and provides a thorough presentation of his approach.

${ }^{10}$ In the special issue on von Uexküll in Semiotica (2001b), in the first issue of the Journal of Biosemiotics (2005), in the Introduction to Biosemiotics edited by Pattee (2008a), and in the first volume of Biosemiotics (2008b).
} 
dialogue with biosemioticians, beyond merely influencing them (more or less) through his earlier work. But, what kind of influence?

\section{Some Divergences and Convergences}

For Kull (1999b) Pattee is just one forerunner among others in the context of Theoretical Biology; Favareau (2008) includes him also among other precursors but now in a short list; Barbieri considers him as a supplementary eccentric branch (both in the sense of peripheral and of distinctive) and as a precursor without school within what is going to converge into Biosemiotics; Hoffmeyer (and Emmeche) considers him increasingly more as key antecedent and acknowledges the relevance of his work during the 1970s (Hoffmeyer 2002, 106), and so on.

But, the differences begin also to be stressed. Jamsa (2008), for instance, labels Pattee a "biophysical semiotician" (p. 93) and, in pointing out his "broad conception of symbol", cannot but note that it is "in part different from semiotics" (p. 94). Hoffmeyer, as he increases the explicit recognition of Pattee's earlier work, makes an effort to distance himself overtly from him stressing the principle of "code-duality" and criticizes ever more directly Pattee's reluctance to consider semiotically also the dynamics (see, for instance, Hoffmeyer 2000, 2001, 2002). Closely related to this issue, Hoffmeyer (2000, p. 176; 2001, p. 124) has disagreed with Pattee's epistemic cut because, according to him, it makes even more difficult to conceive how life could have emerged, how to bridge the gap between matter and symbols. As we have seen at the end of Section "The Paper ("How Does a Molecule Become a Message")", though, Pattee is well aware of this difficulty and actually it has been to the clarification of this hard problem to which he has dedicated most of his work:

"I will state at the outset that I have not solved this problem. In fact, even after decades of effort I have not made much progress other than clarifying the problem. My approach has been to start at the most elementary level and with the simplest cases where the two categories of matter and symbol might meet in some objective sense (Pattee, 1969).” (2005, p. 283)

In any case, this issue signals perhaps one of the major points of divergence since Hoffmeyer, together with Emmeche, are probably the biosemioticians who more directly have debated with Pattee and, as we have seen in the previous point, they recognized his influence in this issue. While Hoffmeyer highlights the centrality of their theory of "code-duality", Pattee admits that a code implies two dimensions but wonders why should it imply two codes (analog and digital). For him, a code as an instance relating a symbolic description (digital) to a dynamical action (analogic), through the meaning provided by the organizational context in a semantic closure, is enough to account for the fundamentals of life (1982 within the cell, 1986 generalized to other systems). Besides Pattee is very skeptical about the potentialities of an analog code

"The problem with analogs is that they are all special purpose structures like individual molecular messengers that have limited informational capacity and must be interpreted individually." (Pattee 2005, 293) 
He thinks that there might of course be two (or more) codes in different systems but that the simplest logic of living systems does not need it. Certainly, as we have seen already in his 1969 paper (see footnote 5), he is well aware that there is an evolutionary course from that "primeval "ecosystem language" (Pattee 1969, p. 3) to the more precise and sophisticated genetic one and, therefore, he admits with Hoffmeyer (2000) that “... some form of implicit analog codes may have existed as precursors of the explicit discrete codes of present life" (Pattee 2005, 293; see also 2008a, 124-125; 2008b, 164).

There is as well the problem of the point of view. The issue of how to understand code related terms in biology (e.g., the discussion regarding biological information) has several facets (Pattee 2006). An important one points to the risk of anthropocentrism, i.e., of projecting within the organism an external stance, as forcefully denounced by Stuart (1985a, b):

" ... the danger of confounding distinct categories in the sense indicated earlier; namely, those pertaining to the observed physical system and those pertaining to the human observer." (Stuart, 1985b, p. 624).

Nevertheless, this is not as much a problem for Pattee, who insists that "[w]hat I want to avoid is confusing the physics and the semiotics" (Pattee 2005, p. 294), as for those who (including perhaps some biosemioticians prone to pansemiotic positions), at least in practice, consider just one and only one kind of epistemic cut: that of the human observer. Or to say it in other words, those who dissolve the epistemic cut in a continuum. Because, even within the let's say non-pansemiotic consensus, incorporating dynamics into semiosis and throwing over board complementarity, closure and cut gives way to the confusion Stuart is denouncing. Others, as Salthe (eg, 1993, 2005), do explicitly argue and defend this no-cut position from an akin but more general perspective.

In turn, this is linked to a methodological issue. We may address the problem from opposite directions: from life to language or from language to life. Even if, at least Hoffmeyer \& Emmeches's as well as Barbieri's approaches (as well as other's) stem from biology, both professionally and conceptually, it seems that, in general, language takes some precedence. Pattee, notwithstanding, begins the other way around: for him the question has always been not how symbols may stand for things but how do material things become symbolic (Pattee 1995a, 11).

Even with respect to the choice of references, concepts and terms there is a gulf. As we have already seen in a previous quote of his 1969 paper (p. 8-9), he has always been cautious with the assistance that linguistic analogies might offer him and more recently, confronted with semiotic jargon, he has kept that concern:

"While the language of physics is reasonably simple and unambiguous, I discovered quickly that the terminologies of semiotics are so complicated and controversial that I could not hope to find consensus on primitive symbol system terminology. As I stated earlier, linguistic terminology originated at the highest levels with human language and human behavior." (Pattee 2008b, p. 158)

In his attempt to address the problem of the symbol-matter relation, Pattee's longstanding preoccupation has been to find appropriate ways of objectification that may allow us to build explanations or models that, though incapable to erase it, 
manage to circumscribe the agent of this very construction (the scientist, the engineer) to a separate and identifiable locus not to be conflated with the agent of the natural processes to be explained or replicated (Pattee 1995b). His attempt combines a non-foundationalist approach to knowledge based on a generalized and sliding view of the epistemic cut made operational via observable functions performed by specific material constraints relating levels in a hierarchical arrangement. There is no need to begin with any privileged "subject" since it might be introduced as nothing more than just a point in the reference triangle of the sign logic: something means something for some(one)thing.

I cannot pursue it here, but let me suggest that Pattee's approach may contribute to provide a bridge over the gulf that, according to Barbieri (2008a, 2008c), is open between the two main perspectives within Biosemiotics regarding the issue of interpretation, by offering an operative and material understanding of "interpretation" or context even at the organic level. This could further allow Biosemiotics to distinguish itself from pansemiosis (e.g., Taborsky 1999) without either resorting to an anthropomorphic view on interpretation or to a fixed or mechanic view of the code as context free. Pattee's approach benefits from using material, physical constraints, as defined in physics, but operating within a clearly linguistic frame.

No doubt the similarities of approach are also important. Pattee's perspective has always amounted to a full semantic (functional, meaningful) interpretation of code/ message relations. Additionally, he has insisted on the necessity to take into account the pragmatic (contextual, environmental) dimension of that relation in addition to the semantic one and, of course, the syntactic one (which is the only one that informational or computationalist views consider). This basic move, almost naïve from a fully semiotic standpoint, did already imply from a beginning a triadic understanding of symbols fully consistent with Peircean semiotics and its more general conception of signs.

Looking for a coincidence in a more strategic or programmatic side, we may notice that his own lifelong main concern is succinctly formulated in his assessment of which is the main theoretical battleground for biosemiotics as a discipline:

"Biosemiotics will become influential in the biological sciences only if it can persuade biologists that semiotic concepts and terminology are objectively necessary for a full understanding of genetic control. (Pattee 2008b, p. 149)

\section{Conclusion: Relevance and Resonance}

Accepting that labels and denominations are surely secondary, we may quite safely maintain that Pattee is not properly a biosemiotician. His perspective has not been and it is not semiotic. His use of linguistic vocabulary: language, code, symbol, ... is just in plain terms and not as part of a specialized terminology. Furthermore, turning to his theoretical development, it is quite clear that, at first, he did not know and did not intend anyway to follow a (bio)semiotic path. On the one hand, his initial work precedes bosemiotics as such and, on the other, he did not have any productive contact with other proper precursors, as Sebeok, neither more in general with the wider Semiotics community. Now he knows the field and he obviously accepts some 
degree of tuning but he continues to use his concepts and (ordinary) terms developed over the years in a highly original and coherent fashion.

From the side of Biosemiotics, we should as well reckon that Pattee had no direct influence in the birth or development of Biosemiotics as such. The field began to mature without taking him into account (despite the ensuing amendment brought about by the natural effort of any new field to identify precursors, friends or potential allies) and most probably without him being aware of it until very recently. Pattee neither has had any decisive role in the expansion and confluence of perspectives conquered lately, together with an incipient institutionalization as discipline (gatherings, society, journals, books). But, as we have seen, now both he is taken into account (even if critically) and he refers to the field (even if critically).

In addition, it is also quite important to notice that Pattee has had no strong aspiration to propositions of global and encompassing perspectives alternative to established scientific theories or paradigms. The main reason being his advocacy of complementary rather than one-sided views (see, i.e., Pattee 2001b, pp. 353-355), it goes together with a dislike of wholesale condemnations. And he is quite clear at this respect:

"By focussing only on either the dynamics or the semiotics, both these approaches completely miss the essential function of symbol/matter and matter/symbol transformations that make life and meaning possible. I also believe it is counterproductive when structuralists and biosemioticians put so much of their efforts into undecidable philosophical criticisms of molecular genetics and neo-Darwinian evolution theory" (Pattee 2001b, 354-355, italics in the original)

Fighting for a discernible and meaningful middle point in terms of complementarity is a battle to which Pattee has been forced more than once and in several arenas: origin of life, hierarchy theory, cognition, notion of life, artificiality, etc. His work in all those areas has been guided by an unrepentant epistemological position ${ }^{11}$ stemming from his formation as a physicist worried by deep philosophical issues: "The symbol-matter relation is a problem just because any answer must incorporate both types of models with their differing epistemologies" (Pattee 2008b, p. 150)

In conclusion, I would therefore say that his influence has not been a direct one but rather an indication of the relevance of his ideas and the resonance of his hypothesis with those of biosemiotics.

Acknowledgments I wish to thank Joanna Raczaszek-Leonardi her insightful review and very helpful comments and criticisms. I also wish to thank Howard Pattee his encouraging reaction and willingness to contribute a response. I gratefully acknowledge the funding provided to our research group by the Ministry of Science and Innovation (FFI2008-06348-C02-C01/FISO) and the Basque Government (IT250-07).

\footnotetext{
${ }^{11}$ Which I have elsewhere labeled "internally interactionist" (Umerez 2001a, p. 161). See also, for instance, the discussion regarding interactionism in the Introduction to the collective book on the Developmental Systems Approach/Theory Cycles of Contingency (Oyama et al. 2001) and Oyama's (2001) chapter in that book to take into account further difficulties of such a sometimes apparently standard position.
} 
I want to thank C. Emmeche who, from the very beginning at the conference, encouraged me to write down this paper. Since that year not only Pattee has written new papers but also the very field of Biosemiotics has had an outstanding development, exemplified by several books and manuals as well as by the launching of this journal (and its predecessor). Certainly this last decade has witnessed an unprecedented grow in unequivocally biosemiotician literature, accelerating at an increasing pace every year, not easy to cope up with. Notwithstanding, I claim that the main argument put forward at that meeting may be upheld with due minor amendments in order to comply with these recent contributions.

\section{References}

Barbieri, M. (1981). The ribotype theory on the origin of life. Journal of Theoretical Biology, 91, 545-601. Barbieri, M (2008a) Editorial. The challenge of Biosemiotics. In M. Barbieri (ed.), Introduction to Biosemiotics (pp. ix-xii). Berlin: Springer.

Barbieri (2008b) Has Biosemiotics come of age? And Postscript. In M. Barbieri (ed.), Introduction to Biosemiotics (pp. $101-113)$. Berlin: Springer.

Barbieri, M. (2008c). What is biosemiotics? Biosemiotics, 1(1), 1-3.

Barbieri, M. (2008d). Biosemiotics: a new understanding of life. Naturwissenschaften, 95, 577-599.

Barbieri, M. (2009) A Short History of Biosemiotics?. Biosemiotics, 2(2), 221-245

Beadle, G., \& Beadle, M. (1966). The language of life. An introduction to the science of genetics. New York: Doubleday.

Beurton, P., Falk, R., \& Rheinberger, H.-J. (eds). (2000). The concept of the gene in development and evolution. Historical and epistemological perspectives. Cambridge: Cambridge University.

Cariani, P. (1989) On the design of devices with emergent semantic functions. PhD. Diss., State University of New York at Binghamton.

de Chadarevian, S. (2002). Designs for life: Molecular biology after World War II. Cambridge: Cambridge University.

Developmental Biology (2009) 325:1-3

Doyle, R. (1997). On beyond living. Rhetorical transformations of the life sciences. Stanford: Stanford University.

Emmeche, C. (1991). A semiotical reflection on biology, living signs and artificial life. Biology and Philosophy, 6, 325-340.

Emmeche, C., \& Hoffmeyer, J. (1991). From language to nature. The semiotic metaphor in biology. Semiotica, 84(1/2), 1-42.

Emmeche, C., \& Hoffmeyer, J. (2005). Foreword to the reprinting of code-duality and the semiotics of nature. Journal of Biosemiotics, 1, 35-85.

Etxeberria, A., \& Umerez, J. (2006). Organismo y organización en la biología teórica ¿Vuelta al organicismo? Ludus Vitalis, 16(26), 3-38.

Favareau, D. (2008). The evolutionary history of biosemiotics. In M. Barbieri (Ed.), Introduction to biosemiotics (pp. 1-67). Berlin: Springer.

Florkin, M. (1974) Concepts of molecular biosemiotics and molecular evolution. In M. Florkin \& E. H. Stotz (eds.) Comprehensive Biochemistry 29A: 1-124.

Gould, S. J. (1995). 'What is life?' as a problem in history. In M. P. Murphy \& L. A. J. O’Neill (Eds.), What is life? The next 50 years (pp. 25-39). Cambridge: Cambridge University.

Hoffmeyer, J. (2000). Code-dualty and the epistemic cut. In J. R. L. Chandler \& G. Van de Vijver (Eds.), Closure. Emergent Organizations and their Dynamics (Annals of the New York Academy of Sciences, vol. 901) (pp. 175-186). New York: The New York Academy of Sciences.

Hoffmeyer, J. (2001). Life and reference. BioSystems, 60(1/3), 123-130.

Hoffmeyer, J. (2002). Code duality revisited. SEED Journal (Semiotics, Evolution, Energy, and Development), 2(1), 98-117.

Hoffmeyer, J., \& Emmeche, C. (1991). Code-duality and the semiotics of nature. In M. Anderson \& F. Merrell (Eds.), On semiotic modeling (pp. 117-166). New York: Mouton de Gruyter.

Jamsa (2008) Semiosis In Evolution. In M. Barbieri (ed.) Introduction to Biosemiotics, pp. 69-100.

Judson, H.F. (1979[1996]) The Eight Day of Creation. The Makers of the Revolution in Biology. New York: Simon and Schuster [exp. ed., Plainview, NY: Cold Spring Harbor Laboratory Press]

Kay, L. E. (1993). The molecular vision of life: Caltech, the Rockefeller Foundation, and the rise of the new biology. Oxford: Oxford University. 
Kay, L. E. (2000). Who wrote the book of life. A history of the genetic code. Stanford: Stanford University.

Keller, E. F. (1995). Refiguring life. Metaphors of twentieth-century biology. New York: Columbia University.

Keller, E. F. (2000). The century of the gene. Cambridge: Harvard University.

Keller, E. F. (2002). Making sense of life. Explaining biological development with models, metaphors and, machines. Cambridge: Harvard University.

Kelly, M. F. (1987) Natural and Artificial Symbol Systems. Construction and computation in a simple organism. PhD. Diss., State University of New York at Binghamton.

Kull, K. (1993). Semiotic paradigm in theoretical biology. In K. Kull \& T. Tiivel (Eds.), Lectures in theoretical biology. The second stage (pp. 52-62). Tallinin: Estonian Academy of Sciences.

Kull, K. (1999a). On the history of joining bio with semio: F.S. Rothschild and the biosemiotic rules. Sign Systems Studies, 27, 128-138.

Kull, K. (1999b). Biosemiotics in the twentieth century: a view from biology. Semiotica, 127(1/4), 385-414.

Kull, K. (2005). A brief history of biosemiotics. Journal of Biosemiotics, 1, 1-34.

Minch, E. (1988) Representation of hierarchical structure in evolving networks. PhD. Diss., State University of New York at Binghamton.

Moore, W. (1989). Schrödinger. Life and thought. Cambridge: Cambridge University.

Morange, M. (1994[2003]) Histoire de la biologie moléculaire. Paris: La Découverte.

Moreno, A., Etxeberria, A., \& Umerez, J. (2008). The Autonomy of Biological Individuals and Artificial Models. BioSystems, 91(2), 309-319

Moss, L. (2003). What genes can't do. Cambridge: MIT.

Olby, R. (1974[1994]) The Path to the Double Helix. The Discovery of DNA. Seattle, WA: University of Washington Press [rev. ed., New York: Dover].

Oyama, S. (2001) Terms In Tension. What Do You Do When All The Good Words Are Taken. In S. Oyama, P.E. Griffiths \& R.D. Gray (eds.) Cycles of contingency, pp. 177-193.

Oyama, S., Griffiths, P. E., \& Gray, R. D. (eds). (2001). Cycles of contingency. Developmental systems and evolution. Cambridge: MIT.

Pattee, H. H. (1967). Quantum mechanics, heredity and the origin of life. Journal of Theoretical Biology, $17,410-420$.

Pattee, H. H. (1968). The physical basis of coding and reliability in biological evolution. In C. H. Waddington (Ed.), Towards a theoretical biology 1, Prolegomena (pp. 67-93). Edinburgh: Edinburgh University.

Pattee, H. H. (1969). How does a molecule become a message? Developmental Biology Supplement, $3,1-16$.

Pattee, H. H. (1972). Laws and constraints, symbols and languages. In C. H. Waddington (Ed.), Towards a theoretical biology 4, essays (pp. 248-258). Edinburgh: Edinburgh University.

Pattee, H. H. (1977). Dynamic and linguistic modes of complex systems. International Journal of General Systems, 3, 259-266.

Pattee, H. H. (1978). The complementarity principle in biological and social structures. Journal of Social and Biological Structures, 1, 191-200.

Pattee, H. H. (1979). The complementarity principle and the origin of macromolecular information. BioSystems, 11, 217-226.

Pattee, H. H. (1982). Cell psychology: an evolutionary approach to the symbol-matter problem. Cognition and Brain Theory, 4, 325-341.

Pattee, H. H. (1986). Universal principles of measurement and language functions in evolving systems. In J. L. Casti \& A. Karlqvist (Eds.), Complexity, language, and life: mathematical approaches (pp. 268-281). Berlin: Springer.

Pattee, H.H. (1989). Simulations, realizations, and theories of Life. in C. Langton (Ed.), Artificial Life (pp. 63-77). Redwood City, CA: Addison-Wesley

Pattee, H. H. (1995a). Evolving self-reference: matter, symbols, and semantic closure. Communication and Cognition. Artificial Intelligence, 12(1-2), 9-27.

Pattee, H. H. (1995b). Artificial life needs a real epistemology. In F. Morán, A. Moreno, J. J. Merelo \& P. Chacón (Eds.), Advances in artificial life (pp. 23-38). Berlin: Springer.

Pattee, H. H. (1997). The physics of symbols and the evolution of semiotic controls. In M. Coombs \& M. Sulcoski (Eds.), Control mechanisms for complex systems: Issues of measurement \& semiotic analysis (proccedings) (pp. 9-25). Las Cruces: New Mexico State University.

Pattee, H. H. (2001a). The physics of symbols: bridging the epistemic cut. BioSystems, 60(1/3), 5-21.

Pattee, H. H. (2001b). Irreducible and complementary semiotic forms. Semiotica, 134(1/4), 341-358. 
Pattee, H. H. (2005). The physics and metaphysics of biosemiotics. Journal of Biosemiotics, 1(1), $281-301$

Pattee, H. H. (2006). The physics of autonomous biological information. Biological Theory, 1(3), 224226.

Pattee, H. H. (2007). Laws, constraints, and the modeling relation-history and interpretation. Chemistry \& Biodiversity, 4, 2272-2295.

Pattee, H.H. (2008a) The Necessity of Biosemiotics: Matter-Symbol Complementarity. In M. Barbieri (ed.) Introduction to Biosemiotics, pp. 115-132.

Pattee, H. H. (2008b). Physical and functional conditions for symbols, codes and languages. Biosemiotics, $1(2), 147-168$.

Pearson, K. (1892 [2004]). The Grammar of Science. New York: Dover (also available online)

Rheinberger, H.J. (2000) Gene concepts: Fragments from the perspective of molecular biology. In P. Beurton eta al. (eds.), pp. 219-239.

Rocha, L. (ed.) (1995) Self-Reference in Cognitive and biological systems. Communication \& CognitionArtificial Intelligence 12(1/2): 2-222 (special issue).

Rocha, L. (ed.) (2001a) The Physics and Evolution of Symbols and Codes - Reflections on the Work of Howard Pattee. BioSystems 60(1/3): 1-181

Rocha, L. (2001b). Evolution with material symbol systems. BioSystems, 60(1/3), 95-121.

Rotschild, F. S. (1962). Laws of symbolic mediation in the dynamics of self and personality. Annals of the New York Academy of Sciences, 96, 774-784.

Ruiz-Mirazo, K., Umerez, J., \& Moreno, A. (2008). Enabling conditions for 'open-ended evolution'. Biology \& Philosophy, 23(1), 67-85.

Salthe, S. (1993). Development and evolution: complexity and change in biology. Cambridge: MIT.

Salthe, S. (2005). Meaning in nature: placing biosemiotics within pansemiotics. Journal of Biosemiotics, $1,267-280$.

Sarkar, S. (ed). (1996). The philosophy and history of molecular biology: new perspectives. Dordrecht: Kluwer.

Schrödinger, E. (1944). What is life? Cambridge: Cambridge University.

Sebeok, T. A. (1963). Communication among social bees; porpoises and sonar; man and dolphin. Language, 39, 448-466.

Sebeok, T. A. (1972). Perspectives in zoosemiotics. The Hague: Mouton.

Sebeok, T. A. (2001). Biosemiotics: its roots, proliferation, and prospects. Semiotica, 134(1/4), 61-78.

Stepeanov, J. S. (1971). Semiotika. Moscow: Nauka.

Stuart, C. I. J. M. (1985a). Physical models of biological information and adaptation. Journal of Theoretical Biology, 113(3), 441-454.

Stuart, C. I. J. M. (1985b). Bio-informational equivalence. Journal of Theoretical Biology, 113(4), 611-636.

Taborsky, E. (1999). Semiosis: the transformation of energy into information. Semiotica, 127, 599646.

Umerez, J. (1995). Semantic closure: A guiding notion to ground artificial life. In F. Morán, A. Moreno, J. J. Merelo \& P. Chacón (Eds.), Advances in artificial life (pp. 77-94). Berlin: Springer Verlag.

Umerez, J. (1998). The evolution of the symbolic domain in living systems \& artificial life. In G. van de Vijver, S. Salthe \& M. Delpos (Eds.), Evolutionary systems. Biological and epistemological perspectives on selection and self-organization (pp. 377-396). Dordrecht: Kluwer.

Umerez, J. (2001a). H. Pattee's theoretical biology. A radical epistemological stance to approach life, evolution and complexity. BioSystems, 60(1/3), 159-177.

Umerez, J. (2001b). Howard H. Pattee's bibliography. BioSystems, 60(1/3), 179-181.

Umerez, J. (2007) Waddington's Symposia. A Retrospective Assessment. In International Society for the History, Philosophy and Social Studies of Biology 2007 Meeting, University of Exeter.

van de Vijver, G., Salthe, S. \& Delpos, M. (eds.) (1998) Evolutionary Systems. Biological and Epistemological Perspectives on Selection and Self-Organization. Dordrecht: Kluwer.

van de Vijver, G., \& Chandler, J. R. L. (2000). Closure. Emergent organizations and their dynamics (Annals of the New York Academy of Sciences, vol. 901). New York: The New York Academy of Sciences.

von Neumann, J. (1966) Theory of Self-reproducing Automata (edited and completed by A. W. Burks). Urbana, Ill: University of Illinois Press.

Waddington, C.H. (ed.) (1968-1972) Towards a Theoretical Biology (4 volumes). Edinburgh / Chicago, IL: Edinburgh University Press / Aldine [Vol. 1, Prolegomena (1968); vol. 2, Sketches (1969); vol. 3, Drafts (1970); vol. 4, Essays (1972)]. 
Waddington, C.H. (1972) Epilogue. In C.H. Waddington (ed.) Towards a Theoretical Biology. Essays, vol. 4, pp. 283-289.

Waters, D.P. (1990) Natural symbol systems: The evolution of linguistic constraints on fit and function. $\mathrm{PhD}$. Diss., State University of New York at Binghamton.

Yoxen, E. J. (1979). Where does Schrödinger's "What is Life?" belong in the history of molecular biology? History of Science, 17, 17-52. 